\title{
DIDÁCTICA DE LAS CIENCIAS PARA UNA CIUDADANÍA CRÍTICA. REFLEXIONES Y PRÁCTICAS CONTEXTUALIZADAS PARA PROBLEMÁTICAS DE AMBIENTE Y SALUD
}

\author{
GONZALO MIGUEL ANGEL BERMUDEZI * \\ https://orcid.org/0000-0001-9734-0965 \\ LÍA PATRICIA GARCÍA ** \\ https://orcid.org/0000-0002-2362-2019 \\ KAREN GIMENA CISNERO $0^{*} *$ * \\ https://orcid.org/0000-0001-7713-5577
}

RESUMEN: En este artículo problematizamos el concepto de ciudadanía democrática dado el impacto de las desigualdades sociales en el sistema educativo y, desde una perspectiva política de la alfabetización científica, cuestionamos visiones simplistas sobre la emancipación ciudadana. Con el objetivo de caracterizar cómo ocurren procesos de construcción de ciudadanía crítica y alfabetización científica tendientes a la transformación social, realizamos una investigación de desarrollo en aulas de ciencias naturales. Siguiendo una metodología cualitativa, configuramos casos en función de problemáticas socioambientales relativas a salud y ambiente (huerto agroecológico, dengue/chikungunya/zika y biodiversidad). Así, analizamos, reconocemos y reflexionamos sobre una Didáctica en el territorio de lo público que, desde un abordaje curricular intersticial y de borde, contextualiza las prácticas de enseñanza en problemáticas socioambientales cotidianas.

Palabras clave: Enseñanza de la Ecología. Educación para la Salud. Huerta escolar.

DIDÁTICAS DAS CIÊNCIAS PARA UMA CIDADANIA CRÍTICA. REFLEXÕESE PRÁTICAS CONTEXTUALIZADAS PARA PROBLEMAS AMBIENTAIS E DE SAÚDE

RESUMO: Neste artigo problematizamos o conceito de cidadania democrática frente ao impacto das desigualdades sociais no sistema educacional e, a partir de uma perspectiva política da alfabetização científica, questionamos visões simplistas sobre a emancipação
*Profesor y Doctor en Ciencias Biológicas, y Biólogo por la Universidad Nacional de Córdoba (UNC). Profesor Titular de Didáctica General y Didáctica Especial en la Facultad de Ciencias Exactas Físicas y Naturales (FCEFyN) de la UNC. Miembro de la Carrera de Investigador Científico del Consejo Nacional de Investigaciones Científicas y Técnicas (CONICET). Docente de posgrado en UNC, Universidad Nacional de La Plata, Universidad Nacional del Litoral y Universidad Nacional de Río Cuarto. Grupo de investigación Communicare. E-mail: gbermudez@unc.edu.ar.

* * Magíster y Especialista en Gestión Ambiental por la Universidad Nacional de San Luis, y Bióloga por la UNC. Adscripta en la FCEFyN y docente en Institutos Provinciales de Enseñanza Media (IPEM 268, IPEM 270, IPET 357 e IPEMyT 24). Grupo de investigación Communicare. E-mail: liapgarcia@gmail.com.

***Profesora y estudiante de Ciencias Biológicas por la UNC Ayudante de investigación en Didáctica Especial, Aspirante a adscripta y Becaria de extensión universitaria (FCEFyN, UNC). Docente en institutos de educación secundaria. Grupo de investigación Communicare. E-mail: karen.cisnero@mi.unc.edu.ar.

\footnotetext{
I Universidad Nacional de Córdoba, Facultad de Ciencias Exactas Físicas y Naturales (FCEFyN), Departamento de Enseñanza de la Ciencia y la Tecnología, Córdoba, Provincia de Córdoba - Argentina.
} 
cidadã. Para caracterizar como ocorrem os processos críticos de construção da cidadania e de alfabetização científica tendente à transformação social, realizamos pesquisas de desenvolvimento em salas de aula de ciências naturais. Seguindo uma metodologia qualitativa, configuramos casos com base em problemas socioambientais relacionados à saúde e ao meio ambiente (horta agroecológica, dengue/zika/chikungunya e biodiversidade). Assim, analisamos, reconhecemos e refletimos sobre uma Didática no território do público que, a partir de uma abordagem curricular intersticial e de ponta, contextualiza as práticas docentes nos problemas socioambientais do cotidiano. Palavras-chave: Ensino de Ecologia. Educação em Saúde. Horta escolar.

SCIENCE EDUCATION FOR CRITICAL CITIZENSHIP. REFLECTIONS AND CONTEXTUALIZED PRACTICES FOR ENVIRONMENTAL AND HEALTH ISSUES

ABSTRACT: In this article we problematize the concept of democratic citizenship given the impact of social inequalities in the educational system and, from a political perspective of scientific literacy, we question simplistic views on citizen emancipation. In order to characterize how the processes of construction of critical citizenship and scientific literacy tending to social transformation occur, we carried out development research in natural science classrooms. Following a qualitative methodology, we configure cases based on socioenvironmental problems related to health and the environment (agroecological garden, dengue/zika/chikungunya and biological diversity). Thus, we analyze, recognize and reflect on a Didactics in the territory of the public sector that, from an interstitial and cutting edge curricular approach, it contextualizes teaching practices in everyday socio-environmental issues.

Keywords: Ecology Teaching. Health Education. School garden. 


\section{INTRODUCCIÓN}

La institución escolar viene atravesando problemáticas socio-culturales, económicas y ambientales, además de las propias del sector, que ponen en tensión el rol de lo que enseña, su papel en la sociedad y sus prácticas pedagógicodidácticas (MASSARINI; SCHNEK, 2015). Surge así la necesidad de revisar el concepto de ciudadanía, al cual se le han atribuido distintos adjetivos (activa, digital, transformadora, crítica, etc.) que intentan profundizar en el sentido que el ejercicio ciudadano tiene en nuestros días (LEVINSON, 2010; RAMOS, 2016).

En este contexto, nos preguntamos ¿cuál es el concepto de ciudadanía está detrás de las políticas y modelos culturales pasados y actuales? Tal y como expresan Pinhão y Martins (2016), la idea de ciudadanía sólo tiene sentido en democracia, por lo que, como decía Aristóteles en la Antigüedad, "el que es ciudadano en una democracia con frecuencia no es ciudadano en una oligarquía" (DUBET, 2003, p.220). Sin embargo, no todos los modelos de ciudadano poseen una ética expresada en prácticas educativas dirigidas a su formación democrática y que, para ello, problematicen las desigualdades e injusticias sociales (PINHÃO; MARTINS, 2016). Por esto consideramos que, como señalan Benedicto y Morán (2003), "cualquier reflexión sobre la construcción de la ciudadanía necesita preguntarse acerca de los procesos de aprendizaje de las identidades, los contenidos y los recursos que permiten un pleno ejercicio de esta condición” (p. 8).

Lo expresado lleva a cuestionarnos: ¿cómo es una didáctica de las ciencias naturales que sea capaz de llevar a cabo prácticas de enseñanza que promuevan la construcción de una ciudadanía crítica y con participación en decisiones sociocientíficas? ¿Qué rol adquiere, desde esta perspectiva, la alfabetización científica? ¿Cuáles son las oportunidades escolares para que el estudiantado desarrolle las capacidades necesarias implicarse plenamente en un ámbito social transformador?

En función de estas preguntas hemos definido el objetivo de este trabajo, que trata de poder caracterizar cómo ocurren, en clases de ciencias naturalesBiología de escuela secundaria, procesos de construcción de ciudadanía crítica y alfabetización científica tendiente a habilitar la transformación social. Para ello, nuestro grupo de investigación ha llevado a cabo un proceso sistematización de experiencias, reflexión y análisis de antecedentes que, por nuestro posicionamiento político, determinó la necesidad de escribir y compartir el presente artículo. Así, hemos configurado tres casos en los que desarrollamos e investigamos nuestra perspectiva en prácticas de enseñanza contextualizadas que promueven, a su vez, las reflexiones que nutren y resignifican estas mismas acciones y posicionamientos.

Para aportar al objetivo, concretamos las cuestiones generales en las siguientes preguntas de investigación, las que, siendo más específicas, orientarán los análisis y discusión de resultados:

i) ¿Cómo se establecen puentes entre los conocimientos y concepciones de las y los estudiantes y el conocimiento biológico escolar, de formas que impliquen aplicación de códigos disciplinares en problemáticas cercanas?

ii) ¿Cómo el trabajo con contenidos y formas propias del trabajo científico 
pueden responder a temáticas cotidianas y socialmente vivas que pongan en discusión elementos para la transformación social?

iii) Los contenidos de los diseños curriculares, ¿̇on más el punto de partida del conocimiento escolar o el de llegada, a través de las actividades y aprendizajes sobre problemáticas socialmente relevantes?

iv) ¿Cómo el desarrollo de determinadas actividades promueve el involucramiento y participación de las y los estudiantes de forma genuina y que trascienda las paredes del aula, extendiéndose a/incluyendo otros miembros de la comunidad?

Si bien nuestro camino está situado en instituciones de educación pública de la Provincia de Córdoba, Argentina, consideramos que este texto puede constituir una contribución tanto al campo teórico de la didáctica general y de la didáctica de las ciencias, como a las prácticas de enseñanza en el país y la región. Intentaremos responder primero inquietudes desde un marco sociohistórico y político, y así posicionarnos en una didáctica de las ciencias naturales que, sostenemos, nos interpela para formar en ciudadanía como camino hacia una mayor profundización y extensión de la democracia.

\section{UNREPASO SOBREEL CONCEPTOOCCIDENTALDE CIUDADANÍA YLACONSOLIDACIÓN DEL ESTADO ARGENTINO}

A veces pienso que se habla de ciudadanía como si fuera un concepto, muy abstracto, con cierta fuerza mágica, como si, cuando la palabra ciudadanía fuera pronunciada, automáticamente, todos la ganasen. [...] No es eso. Es necesario dejar claro que la ciudadanía es una producción, una creación política (FREIRE, 2004, p.127, citado en PINHÃO; MARTINS, 2016).

El sistema educativo viene siendo destinatario de una demanda social inspirada en la creación de condiciones para el ejercicio de la ciudadanía (RAMOS, 2016). Para revisar la temporalidad de los modelos de ciudadano occidental seguiremos a Perissé (2010), quien sostiene que en la antigua Grecia el ciudadano se debía al estado tanto en tiempos de paz como de guerra. La vida política en la polis no permitía la neutralidad, sino que establecía claramente las pautas para el ámbito de las decisiones colectivas. El Estado romano, quien tomara algunas nociones del modelo griego, le otorgó un marco jurídico al concepto de ciudadanía. Con ello, sólo los ciudadanos que se consideraban plenos podían ocuparse de los cargos políticos y religiosos. Sin embargo, a diferencia de lo ocurrido en Grecia, Roma reconocía la existencia del ámbito privado, delimitado por la esfera íntima de las personas.

Avanzando en la historia, y en el marco de las profundas transformaciones que se suceden en Europa con el capitalismo y la revolución industrial, Perissé (2010) afirma que las naciones europeas modernas se fueron estructurando en función de su fe en el progreso, la ciencia y la razón. Tal fue el caso de la República francesa, que intentó formar ciudadanos para alcanzar este ideal a través de un proceso de homogeneización. La garantía de la igualdad ante la ley tuvo como contrapartida la 
imposición de un idioma, una geografía y una historia. Este modelo republicano dio respuesta al individualismo y a la caracterización de ciudadanía en términos de aspectos jurídicos (PINHÃO; MARTINS, 2016). Pero, al presuponer la participación activa de los ciudadanos en el proceso político, eran los valores cívicos los que orientaban la agencia de los sujetos. Así, la ciudadanía republicana se relacionaba tanto con un estatus legal como con la acción de participación en la sociedad.

Esta concepción de ciudadanía ejerció una gran influencia en la consolidación del Estado argentino, al punto que la Constitución de 1853 tuvo como ideal al ciudadano europeo. El fomento de su inmigración hizo necesaria la integración cultural de quienes llegaban, con lo que la obligatoriedad de la educación primaria en 1884 y la conscripción forzosa en el ejército en 1902 fueron acciones destinadas a alcanzar el ideal de homogeneidad (PERISSÉ, 2010). El concepto de ciudadanía argentina quedaba delimitado al estatus legal que otorgaba ciertos derechos y generaba obligaciones (como el voto masculino). En tanto, la educación secundaria y universitaria estaban destinadas a una elite con futuro de obtener cargos políticos. Desde entonces, la noción de ética presentada en este modelo ha venido produciendo prácticas pedagógicas dirigidas a la formación para una buena convivencia, sin problematizar las desigualdades e injusticias sociales (PINHÃO; MARTINS, 2016).

Con los gobiernos peronistas de mediados del siglo XIX y hasta la caída del régimen democrático en 1976 con el golpe cívico-militar, el ciudadano era concebido como un actor político en sentido colectivo. Durante el primer mandato peronista las intervenciones y reformas fueron al principio poco significativas en lo referido a contenidos curriculares, pero la reforma de la constitución de 1949 sentó las bases para una formación estudiantil "que [...] conozca la esencia de los argentinos, la realidad espiritual, económica, social y política de su país, la evolución y la misión histórica de la república argentina y para que adquiera conciencia de la responsabilidad [...]" (citado en CORA; RODRÍGUEZ, 2015, p. 189). Este valor insoslayable de la educación en la formación de la conciencia nacional tuvo su correlato en la creación del espacio curricular "Cultura Ciudadana", ${ }^{1}$ enfocado a valores y saberes para el ejercicio pleno de derechos y la participación pública (CORA; RODRÍGUEZ, 2015).

Con el derrocamiento del tercer mandato de Perón (1973 - 24 de marzo de 1976), la dictadura instaló por la fuerza un modelo neoliberal, persiguiendo a -y forzando la desaparición de- miles de ciudadanos y ciudadanas. Dentro del sector educativo, el estudiantado universitario, y hasta el secundario, sufrió una persecución especial. ${ }^{2} \mathrm{El}$ terrorismo estatal demonizó la esfera pública y persiguió sus expresiones a través de comunicados oficiales, que actualizaban periódicamente prohibiciones de la vida social, la abolición de derechos civiles y el castigo de la acción política. A continuación ensayamos algunas respuestas acerca de cómo la dictadura cívicomilitar argentina y las políticas neoliberales influyeron en el sistema educativo y en sus integrantes. Las consecuencias parecen ser las mismas que una mirada crítica sobre el sistema educativo público latinoamericano es capaz de denunciar en el presente. 


\section{DEL LA SEGMENTACIÓN A LA FRAGMENTACIÓN EDUCATIVA: ¿CAER ${ }^{3}$ EN LA EDUCACIÓN PÚBLICA?}

Mientras se condena el carácter injusto de la segmentación del sistema escolar general, individualmente se tiende a evitar cualquier medida que [...] dificulte la decisión de colocar a los hijos en establecimientos donde sólo concurran sus 'iguales'. (TEDESCO, 2017, p. 209)

La privatización ha adquirido un notable protagonismo desde finales del decenio de 1970 y principios de 1980, en particular, la educativa. A fines de los ' 80 s, Braslavsky (1989) mostró que la existencia de circuitos diferenciados de calidad en la educación argentina entre el sector público y privado de la década anterior había desencadenado una segmentación educativa. Ésta no sólo refería a la separación de las gestiones, sino al ofrecimiento de prestaciones distanciadas en lo público y privado. ${ }^{4}$ En el contexto de un marco legal promotor, las instituciones escolares definían autónomamente los patrones para seleccionar la población estudiantil, profundizando las diferencias entre sectores sociales (VELEDA, 2012). Como consecuencia, Tiramonti (2005) señala que una sociedad que se había pensado a sí misma con aspiraciones de igualdad e integración, comenzó polarizarse.

En la década de los '90 tuvo lugar un afianzamiento del modelo neoliberal en Latinoamérica, con la consecuente desaparición del rol del Estado (PERISSÉ, 2010) y la cristalización de lo que iniciara en la década anterior (TIRAMONTI, 2005). Bajo el modelo de ciudadanía liberal clásico, el Estado representa la administración pública, quien debería asegurar los derechos civiles. Sin embargo, la creciente fragmentación social llevó a hablar de una ciudadanía resignada, individualista ${ }^{5}$ y formal, pues las personas poseían el estatus jurídico de ciudadano pero no gozaban efectivamente de sus derechos (PERISSÉ, 2010). En este marco, la federalización del sistema educativo en 1993 pasó a manos de las provincias su gestión y financiamiento, y amplió la obligatoriedad a los tres primeros años de la escuela secundaria. Sin embargo, la existencia de circuitos diferenciados de calidad, en los que "el tipo de saberes, valores, creencias, los patrones de socialización que caracterizan a un [... sector educativo] no tienen casi nada que ver con los que caracterizan a otro" (TIRAMONTI, 2005, p.100) consolidó una fragmentación educativa (TIRAMONTI, 2004). Esta marcada heterogeneidad escolar y estratificación social, ${ }^{6}$ que identificó la transición al siglo XXI (CERVINI, 2006), se sostenía por el principio de que aquellos culturalmente iguales (herencia familiar) tienden a estar institucionalmente juntos. En este sentido, Gessaghi (2017) remarca que las escuelas privadas han mantenido su relevancia en las experiencias formativas de las familias tradicionales, aun cuando éstas no destaquen por su alto nivel académico. ${ }^{7}$

En este punto es importante pensar en las formas en las que la fragmentación educativa puede haber influido en los aprendizajes. Al respecto, el Programa para la Evaluación Internacional de Alumnos ${ }^{8}$ (PISA) viene relevando desde hace una década que las escuelas favorecidas económicamente de Argentina, a las que asisten estudiantes de los sectores socioeconómicos más acomodados, tienden a tener más recursos educativos y a obtener mejores desempeños en ciencias (Organisation for Economic Cooperation and Development [OECD], 2010a). Más aún, cuanto mayor es la ventaja socioeconómica, mayor es el aumento marginal en el rendimiento de los estudiantes (OCDE, 2010b). 
En los últimos años se han instalado en Latinoamérica tendencias orientadas al logro de una mayor equidad social y, con ellas, la educación como bien público y la universalización de su acceso (LOCATELLI, 2018; TEDESCO, 2017). A pesar de que la matrícula en el sector privado de Argentina continuó su expansión en los primeros años del siglo XXI (GESSAGHI, 2017), muchas familias de clase media se resisten aún hoy y permanecen en las escuelas públicas (NARODOWSKI; GOTTAU, 2017). Aquí, lo público/estatal destaca como valor.' Los hijos de estas familias, tanto como otros que no podrían pagar una institución privada, no “caen” en la escuela pública sino que la eligen.

La discusión de la agenda educativa post-2015 marca, según Tedesco (2017), que si bien se registran avances y progresos en cuanto a igualdad social e inclusión en el sistema educativo, el ritmo en que lo hacen es significativamente lento. Incluso, ante la actual tendencia a la restauración conservadora y de modelos neoliberales (DO NASCIMENTO et al., 2019), los procesos de mercantilización educativa (LOCATELLI, 2018) indican que la fragmentación continuará profundizándose (CERVINI, 2002). Sin embargo, los alcances del trabajo escolar y el papel de las variables sociales no han sido abordados suficientemente por la Didáctica (FELDMAN, 2018). Antes de aportar a ello, buscaremos posiciones acerca de cómo vemos las relaciones entre la expresión de una ciudadanía democrática y crítica con la enseñanza de las ciencias naturales.

\section{DESDE 'LEER Y ESCRIBIR' A CUESTIONAR LA LINEALIDAD ENTRE EL SABER Y LA PARTICIPACIÓN EN DECISIONES SOCIOCIENTÍFICAS}

[...] el conocimiento científico como prerrequisito para el desarrollo de la ciudadanía vincula la participación política con un tipo de racionalidad restringida. [...] [Hemos de] romper con algunos discursos pedagógicos basados en la formación para una buena convivencia social, porque el problema de la ciudadanía es conflictivo y no armonioso. (PINHÃO; MARTINS, 2016, p.27)

Originalmente, la alfabetización, o el dominio de determinados códigos indispensables para el desempeño dentro de la sociedad (TEDESCO, 2017), estaba circunscripta a procesos de lectura y escritura en la resolución de cuestiones básicas de la vida cotidiana. Con el tiempo, el concepto de alfabetización ha sido reconocido, más bien, como un proceso continuo de adquisición de habilidades y conocimientos según los contextos de producción y uso, tanto individuales como sociales (MARTÍNEZ et al., 2014). A su vez, dado el impacto de la ciencia y la tecnología en la vida de las personas, desde comienzos del siglo XXI se comenzó a poner énfasis en la búsqueda de la alfabetización científica, tecnológica y digital (TEDESCO, 2017). La primera se revela como la capacidad construida para el análisis y la evaluación de situaciones que permiten o culminan en la toma de decisiones y el posicionamiento (SASSERON, 2015). Para apuntar a ella, la enseñanza de las ciencias debió despojarse primero de un carácter propedéutico (OSORIO; MARTINS, 2010) y proponerse contribuir a una participación ciudadana genuina (MEINARDI, 2008).

La perspectiva política de la alfabetización científica -a la que adherimospermite cuestionar, según Meinardi (2016), visiones simplistas que consideran que la 
emancipación y la participación ciudadana son consecuencia directa del dominio del conocimiento científico. Más bien, pensar la ciudadanía y la enseñanza de las ciencias requiere desnaturalizar la idea de una sociedad dada con un orden a priori, en el que cada ciudadano debe cooperar para su funcionamiento (PINHÃO; MARTINS, 2016). Esta construcción, de acuerdo con Arroyo (2010), cuestiona la romantización del proceso educativo que sirve más a la perpetuación del status quo que a la emancipación de los segmentos más desfavorecidos. Para ello, Pinhão y Martins (2016) apuestan a que el profesorado de-construya lógicas abstractas de participación política ancladas en la imagen del sujeto liberal moderno. Lo anterior lleva a preguntarnos cuáles son los fundamentos didácticos necesarios para que la alfabetización científica cuestione el mencionado status quo y genere una participación ciudadana crítica.

\section{UNA DIDÁCTICA DE LAS CIENCIAS NATURALES EN EL TERRITORIO: ACCIONES FUNDAMENTALES ${ }^{10}$ DESDE EL BORDE DEL CURRÍCULUM}

[...] las corporaciones de especialistas y elaboradores del currículum definen el contenido escolar como altos niveles de realización dentro de cada disciplina y las prescripciones curriculares mantienen cierta ajenidad con lo que realmente sucede en las aulas [...] (FELDMAN, 2018, p.140).

Iniciamos este apartado con el reconocimiento de que, tal como sostiene Feldman (2018), "la enseñanza es una práctica siempre situada en coordenadas históricas y sociales específicas" (p. 132) y que el énfasis en el sistema didáctico (maestra/o, estudiantes, saber) ha ido de la mano de una creciente "debilidad del campo para pensar en problemas reales" (p. 133). En este sentido, queremos recuperar la necesidad de una Didáctica en el territorio, que escape de los enfoques instrumentalistas de la enseñanza -centrados en lo estructural-formal (DE ALBA, 2006)- para recobrar las dimensiones humana y político-social de la enseñanza (CANDAU, 1987). Esta Didáctica no sólo se caracteriza por ser reflexiva y contextualizada (MEINARDI, 2008; VILELA; SELLES, 2015; RIVAROSA; DE LONGHI, 2012), sino que lucha contra la subordinación y el silenciamiento del trabajo del profesorado a las políticas curriculares (SELLES; ANDRADE, 2016).

La perspectiva didáctica que sostenemos persigue la formación de ciudadanas y ciudadanos que sean capaces de sortear dificultades y tomar partido críticamente en un sistema socioambiental complejo, desigual y contradictorio, en el que la transversalidad de la acción democrática está en proceso constante de redefinición. Esta didáctica se propone formar una ciudadanía alfabetizada, capaz de actuar tanto en la identificación y resolución de controversias socioambientales como en las visiones y sistemas de valores en los que éstas se inscriben (BAGUER; JERICÓ, 2017). Aquí las y los jóvenes son (y se ven a sí mismos como) ciudadanas y ciudadanos con voces en el presente, no con un sentido potencial o futuro (LEVINSON, 2010). Una Didáctica en el territorio va al encuentro de, tal como expresa Isabel Martins, "el desarrollo de secuencias didácticas para la enseñanza de cuestiones socialmente vivas" (en MEINARDI, 2016, p.80), por lo que los saberes que emergen y resignifican están ligados a las necesidades y preocupaciones de los participantes.

Recuperando la agenda clásica de la Didáctica, defendemos que la 
enseñanza en el territorio llega a los contenidos desde el borde del currículum, a diferencia de lo que propone Litwin (2008), ${ }^{11}$ ya que los diseños y materiales curriculares (no de borde) no necesariamente son actuales y socialmente vivos. ${ }^{12}$ Por el contrario, la vía de ingreso al currículum -en su acepción como objeto de enseñanza- es para una Didáctica en el territorio, más bien, desde el borde de lo explicitado o prescripto como declaración de temas (de centro, o ubicados en el centro). En este sentido, nuestra perspectiva reconoce que la síntesis de elementos culturales (conocimientos, valores, etc.) deriva de un proceso arbitrario, por lo que la conformación de los curricula y propuestas de enseñanza es un campo propicio para el surgimiento de vías de resistencia, oposición y negociación con sectores sociales no hegemónicos (DE ALBA, 2006). De este modo, el currículum explícito y los aspectos estructurales-formales funcionan más bien como una base para proponer contenidos y justificaciones que encuentren fundamentos en la alfabetización científica, la participación democrática y la desigualdad social.

Lo anterior reafirma no sólo que la relación entre las propuestas de enseñanza y los materiales curriculares es artesanal, situada y de carácter multirreferencial (ALLIAUD, 2017), sino que también se encuentra en construcción y proceso constante de legitimación. Para una Didáctica en el territorio y desde el borde del currículum son las problemáticas del contexto las que marcan la ruta de acceso a los contenidos y actividades, puesto que su anclaje reclama de controversias sociocientíficas palpables, que cuestionen el statu quo y que activen vías democráticas para la expresión de una ciudadanía crítica. Esta concepción implica buscar y encontrar lo que Frigerio (1991) llama intersticios curriculares, generados como zonas de incertidumbre o espacios decisionales que los diseños dejan abiertos.

Por último, sostenemos que las acciones y propuestas fundamentales centradas en una Didáctica en el territorio están comprometidas con la emancipación de las y los estudiantes. Ello requiere que el profesorado mire críticamente los saberes áulicos y las relaciones sociales que los definen "para que los estudiantes se hagan responsables del poder, luchen contra la pobreza, la destrucción ecológica, la tergiversación de la historia y el desmantelamiento del estado social" (GIROUX, 2013, p. 23-24). Ahora bien, ¿cómo es capaz de abordar esto la Didáctica? Creemos que las cuestiones referidas a la biodiversidad, la huerta agroecológica y el dengue propician el marco ideal para un abordaje curricular intersticial y en el territorio, ya que entretejen conceptualizaciones y prácticas socioculturales diversas (CORDERO et al., 2012; RIVAROSA; DE LONGHI, 2012), y ofrecen al profesorado la posibilidad de relacionar el instrumental didáctico con los problemas de desigualdad social (FELDMAN, 2018). Con relación a ello, compartimos a continuación relatos y reflexiones de algunas experiencias de investigación, enseñanza y extensión que han permitido construir y resignificar nuestro recorrido teórico-metodológico.

\section{APROXIMACIONES METODOLÓGICAS Y DESARROLLOS}

La didáctica es una disciplina fundamental para comprender la transformación del trabajo en el aula, para planificar una reforma educativa y para entender el sentido de una innovación en la educación. (DÍAZ BARRIGA, 2009, p.53) 
Incluimos en este apartado las decisiones metodológicas adoptadas para el desarrollo de tres experiencias de investigación, docencia y extensión universitaria que, en distintos grados y sin límites precisos (CORDERO et al., 2012), han permitido que nos encontremos, los autores de este artículo, en diferentes momentos de nuestra historia profesional. El proceso seguido puede caracterizarse como de investigación de desarrollo (MÉHEUT; PSILLOS, 2004), en el que las secuencias didácticas se usan como herramienta de investigación e innovación a partir de la práctica, reflexión y revisión de acciones por parte de, en nuestro caso, el grupo docente-investigador-extensionista (KEMMIS; MCTAGGART, 1988).

Acordamos con Díaz-Barriga (2009) en que uno de los modelos más significativos para la construcción de una teoría didáctica es considerar que la disciplina no sólo orienta la práctica, sino que se construye también como resultado del propio trabajo educativo. Así, "la articulación entre lineamientos teóricos y su concreción en estrategias técnicas de enseñanza” (op. cit. p.127) es un elemento constitutivo de la génesis de la presente contribución. En este sentido, coincidimos también con Meinardi (2008) y nos aproximamos a su modelo de construcción de conocimiento didáctico en equipos mixtos de formadores de formadores, profesores, investigadores y profesores en formación inicial, de tal manera de promover la reflexión colectiva y generar conocimiento contextualizado en la complejidad de los escenarios reales. Con ello nos acercamos un abordaje de "los problemas del aula como problemas de investigación [con el fin de] producir prácticas sensibles a la problemática de las poblaciones para las cuales fueron formuladas" (MEINARDI, 2008, p. 3).

Para concretar lo anterior, optamos por una metodología cualitativa, realizando un estudio descriptivo-interpretativo, que integra el estudio de casos. Cada uno de éstos ha sido configurado a partir de los registros de desarrollos de proyectos educativos y secuencias de enseñanza y aprendizaje (SEA) (o unidades didácticas) que vinculan objetivos tanto de intervención pedagógica como de investigación (CHION et al., 2014). El enfoque cualitativo se caracteriza por su holismo y porque las pautas, categorías e interpretaciones se construyen en un proceso de interacción con los datos y la literatura, y por la singularidad de los fenómenos sociales en los que ocurren (LATORRE et al., 2005). A su vez, las SEA han sido reconocidas como herramientas innovadoras que intervienen en problemáticas identificadas para temas y contextos particulares (LÓPEZ-MOTA; MORENOARCURI, 2014). En nuestra contribución, presentamos los casos en función de las siguientes actividades y cuestiones: la huerta agroecológica escolar, dengue/ chikungunya/zika y la conservación de la diversidad biológica. El levantamiento de información fue realizado a través de grabaciones de audio, fotografías propias y del estudiantado, registro de sus carpetas y otras producciones (afiches, notas, evaluaciones, cuestionarios, etc.). Los registros fueron codificados, categorizados y analizados a partir de la identificación de unidades de análisis, orientadas por las preguntas de investigación, las prácticas reflexivas, los posicionamientos teóricos y otros criterios inductivamente emergidos. Los autores triangulamos la selección de fuentes de información, las categorías de análisis, sus interpretaciones y discusiones con los referentes teóricos (CISTERNA, 2005).

Las unidades didácticas y proyectos educativos fueron/son desarrollados en cursos de la educación secundaria de Argentina, que es obligatoria (11-12 a 17-18 
años de edad) y adquiere distintas configuraciones de acuerdo a las jurisdicciones. En la Provincia de Córdoba, el Ciclo Básico ocupa los primeros tres cursos (llamados primero, segundo y tercer año), mientras que los tres años restantes (cuarto, quinto y sexto año) comprenden el Ciclo Orientado. Éste profundiza el estudio del Ciclo anterior en función de delimitaciones disciplinares y perfiles laborales de los egresados. Córdoba adopta las diez orientaciones acordadas con el Consejo Federal de Educación (Ciencias Sociales; Ciencias Naturales; etc.) y, en el caso del presente artículo, hemos trabajado en distintos espacios curriculares o asignaturas del Ciclo Orientado en Ciencias Naturales (COCN), tales como 'Ecología' y 'Educación para la Salud'.

Los tres casos (ver siguiente apartado) vienen siendo -o fuerondesarrolladas en un IPEMyT de la ciudad de Malvinas Argentinas (Provincia de Córdoba, Argentina). Esta localidad está ubicada a en un llano hacia el oriente de Departamento Colón, a $14 \mathrm{~km}$ al Este de la Ciudad de Córdoba (capital de la Provincia homónima, 1,5 millones de habitantes), y conectada con ésta y el país a través de las rutas nacional 19 y provincial A 88. La población es de carácter urbano-marginal y el paisaje se caracteriza por prácticas agropecuarias (monocultivo de soja, con rotación de maíz y trigo) y extracción de suelo para la fabricación de ladrillos. El bosque nativo, originalmente de la región del Espinal, ha prácticamente desaparecido, quedando solamente relictos en los bordes de los campos.

\section{EXPERIENCIASEDUCATIVAS SOBREAMBIENTEY SALUDENLASQUERECONSTRUIMOS LA DIDÁCTICA EN EL TERRITORIO DE LO PÚBLICO}

[...] Freire habilita al educador a transgredir las reglas de la educación dominante para ser partícipe del cambio social, descubriendo, en cada situación histórica en particular, las tareas que puede realizar. (PUIGGRÓS, 2005, p.21)

Presentamos tres casos configurados a partir de la reflexión, revisión y reconstrucción de secuencias de enseñanza y aprendizaje de cuestiones socialmente vivas, relativas al ambiente y la salud.

\section{'Con las manos en la tierra': una huerta agroecológica escolar para situar aprendizajes de Biología y desarrollo sostenible (caso 1)}

La agricultura es un proceso de artificialización de la naturaleza que tiene su origen y una historia vinculada a prácticas del campesinado y comunidades originarias para producir alimentos. Esta capacidad productiva, sostenida en el tiempo, ha sido abordada en los ámbitos académicos desde comienzos de la década del '80 del siglo XX bajo la denominación de agroecología (ALTIERI; NICHOLLS, 2007). Sin embargo, la agricultura convencional ha promovido la simplificación del medio ambiente, reemplazando la diversidad natural y cultural por un número reducido de especímenes, afectando procesos ecosistémicos y bienes ambientales comunes (INTERGOVERNMENTAL SCIENCE-POLICY PLATFORM ON BIODIVERSITY AND ECOSYSTEM SERVICES [IPBES], 2019). En este contexto, la realización de proyectos escolares como huertas agroecológicas constituye una práctica cada vez más habitual (CEBALLOS, 2017). 
Además, los huertos proveen un contexto particular para desarrollar la indagación y participación en prácticas socioambientales críticas (RUIZ; RODRÍGUEZ, 2015; LOPEZ; BENAVIDES, 2014).

Implementaciones y contexto. Nos pusimos como meta construir discursos y prácticas educativas que desde lo ambiental atiendan a las necesidades y emergencias sociales. Para ello, reconocimos a las Huertas Agroecológicas Escolares (HAE) y Comunitarias (HAC) como estrategias que integran de manera interdisciplinar diferentes saberes para el desarrollo sostenible y la valoración de la biodiversidad (BERMUDEZ; DE LONGHI, 2015). Con las manos en la tierra, en esta experiencia se entrecruzan y nutren la teoría y la práctica, tomándose decisiones por mayoría, como, por ejemplo, dónde hacer la huerta, qué especies sembrar y qué alimentos serán elaborados con la cosecha. La implementación de la HAE comenzó en 2001, y desde entonces se viene desarrollando hasta la actualidad de $4^{\circ}$ a $6^{\circ}$ en 'Ecología' y 'Educación para la Salud' (COCN). Con el paso del tiempo, la HAE ha extendido sus fronteras a partir de la propuesta de que las y los estudiantes desarrollen huertas en sus hogares, aportando así beneficios para el bienestar familiar, la economía comunitaria y el cuidado de la naturaleza desde una dimensión colectiva (Figura 1).

Figura 1. Arriba y al centro: Estudiantes elaborando huertas agroecológicas en sus hogares. Abajo: Armado de canteros, perímetros a los mismos y aporte de cobertura vegetal (mulch).
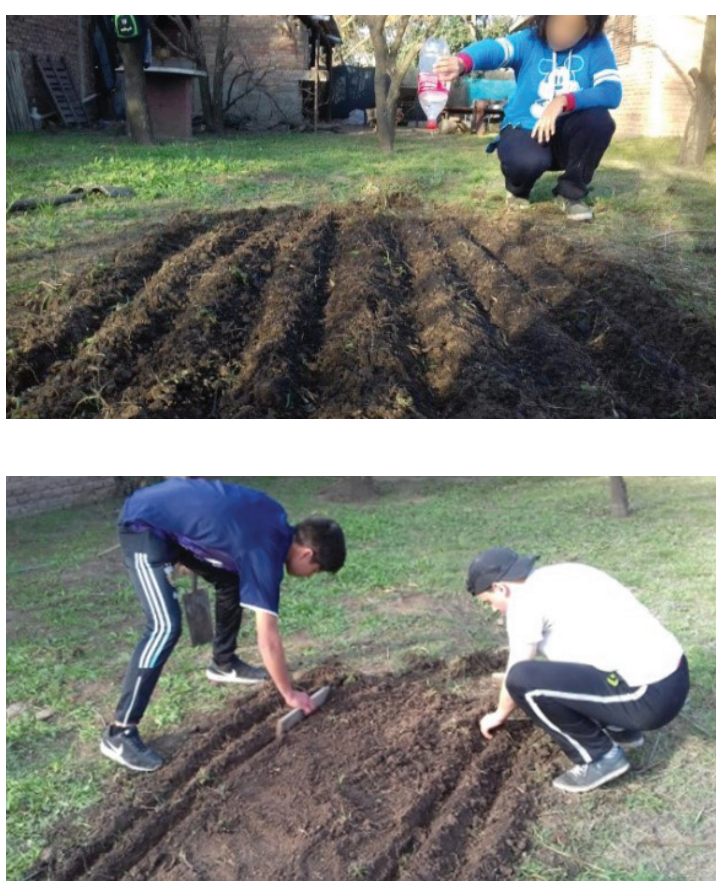


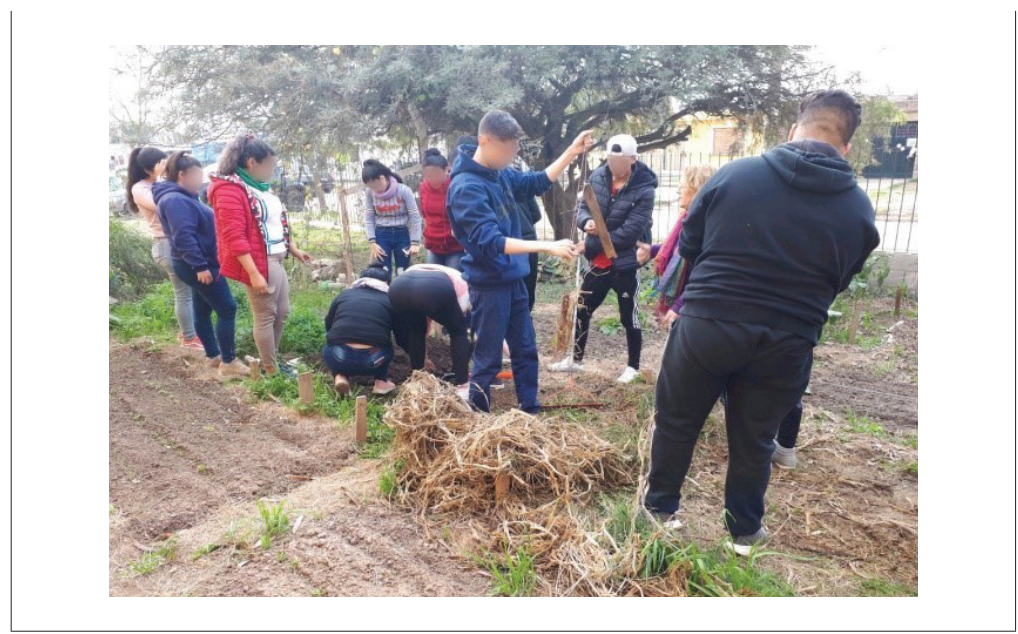

Fuente: Elaboración de los autores.

Actividades y tareas. A través de la huerta abordamos contenidos relacionados con los principios de la agroecología, como la biología del suelo, los tipos de siembra, repiques y trasplantes; ${ }^{13}$ así como también temas tradicionalmente explicitados en los diseños curriculares (las partes de las plantas y su reproducción, las especies clave, las redes tróficas, etc.). Con la HAE producimos alimentos de manera sostenible, con prácticas de manejo que no requieren del uso de agrotóxicos. A su vez, en el cerco perimetral hemos implantado un jardín de plantas aromáticas y medicinales, y, para fomentar aún más la presencia de polinizadores, desde 2017 hemos incorporando a este sector arbustos y hierbas nativas de la ecorregión del Espinal. Con ello también revalorizamos el monte nativo, potenciamos las interacciones biológicas e incrementamos la diversidad (expresada como especies, grupos funcionales y rangos de color, olor y forma).

La huerta comienza año a año indagando las ideas previas del estudiantado acerca de cómo sembrar, los diferentes tipos de cultivos, para luego realizar distintas tareas de inicio ${ }^{14}$ y mantenimiento ${ }^{15}$ de la misma (Figura 1). Varias veces a la semana se monitorean tanto las condiciones en las que se encuentran las plantas como de la fauna asociada y, cuando las temperaturas son bajas, se instalan invernaderos móviles. Además, con residuos orgánicos que las y los estudiantes traen desde sus hogares elaboramos compost y lombricompuesto para fertilizar los suelos. Por último, marcamos anualmente algunas plantas para que lleguen a la etapa del ciclo vital correspondiente a la floración, para luego recolectar sus semillas.

Con la cosecha (acelga, cebolla, calabacín, borraja, perejil, etc.) hemos preparado comidas, por ejemplo, torrejas, canelones, budines, tartas, empanadas, panes rellenos, puré, mermeladas y frutas en almíbar. Estas instancias son vividas por todos con gran alegría y compañerismo. A su vez, el huerto involucra el desarrollo de estrategias dentro del aula, tales como la búsqueda y lectura comprensiva de bibliografía específica, el estudio de casos y el observatorio para análisis de datos. También hemos llevado a cabo juego de roles para discutir las controversias que se suscitan en la sociedad en relación con las diferencias entre la agricultura convencional y la agroecológica. 


\section{Desarrollo de proyectos socio-comunitarios sobre problemáticas de salud contextualizadas: dengue, chikungunya y zika (caso 2)}

Concebimos la salud como un derecho humano inalienable, ligado no sólo a factores biológicos sino también a histórico-culturales. Por ello, hablar de salud implica referirse al trabajo digno y gratificante, la alimentación y vivienda adecuadas, la recreación, el acceso a la información, la educación y la cultura, la afectividad y la vida social (CORDERO et al., 2012). Este concepto adquiere sentido en tanto proceso de construcción colectiva, en el que la participación activa de la población está enfocada, ya no sólo desde un rol de paciente, sino, más bien, como agente de transformación de su realidad (VILELA; SELLES, 2015).

En la escuela secundaria, los contenidos relacionados con la salud y la enfermedad suelen ser abordados a partir de enfoques biologicistas o simplificados, es decir, desde perspectivas perimidas o insuficientes para exponer la complejidad que las atraviesa (CHION et al., 2015). Para el caso de enfermedades transmitidas principalmente por el mosquito Aedes aegypti, el dengue ha adquirido gran importancia en la región, dado que a su epidemia se han incorporado la de chikungunya/zika, que tienen el mismo mosquito como vector (GARELLI et al,, 2017). Según esta perspectiva de salud, el abordaje del dengue/chikungunya/zika requiere de una estrategia educativa integradora, multicausal y multirreferencial que incorpore diferentes saberes, el debate, lo ético, etc. Así, el saber científico podrá encontrar su sentido y limitaciones, y ayudar a desarrollar el pensamiento crítico (MASSARINI; SCHNEK, 2015). Sin embargo, los materiales didácticos e informativos sobre dengue poseen una impronta biomédica, a la vez que proponen actividades de aprendizaje de tipo memorístico (GARELLI et al., 2017).

Implementaciones y contexto. 'Educación para la Salud' es un Espacio de Opción Institucional (EOI) del COCN, y forma parte del mapa curricular para los últimos tres cursos de la educación secundaria (estudiantes de 15/16-17/18 años). Con el tiempo, las temáticas han ido variando según el diagnóstico de prioridades y necesidades del estudiantado y la comunidad educativa, como por ejemplo, además de dengue/zika/chikungunya, las adicciones y la educación sexual integral.

Actividades y tareas. De acuerdo con la necesidad de abordar el control del dengue y enfermedades relacionadas con un enfoque integrado, e incluyendo a la participación comunitaria, las y los estudiantes planifican y llevan a cabo proyectos socio-comunitarios (Figura 2). Éstos son supervisados a medida que las y los estudiantes los idean, para luego presentarlos en un plenario con el objetivo de discutir posibles mejoras. Finalmente, los proyectos son desarrollados en los contextos elegidos, tales como instituciones educativas, feria de ciencias, etc. (Figura 2). Las actividades más frecuentes que el estudiantado ha desarrollado a lo largo de los años (charlas y talleres, presentaciones con maquetas y obras de teatro) han intentado revelar y problematizar situaciones relacionadas con la salud en la vida cotidiana. Como parte de la búsqueda de voces autorizadas, han realizado entrevistas a especialistas en dispensarios locales y hospitales de otras localidades, revisado bibliografía en la biblioteca y en sitios recomendados de Internet. Uno de los aspectos con el que evaluamos los proyectos consiste en identificar y analizar evidencias de conocimiento adquiridas por la población beneficiaria de las acciones 
realizadas. Para ello, se diseñan instrumentos según criterios e indicadores, como por ejemplo, rompecabezas, sopas de letras, acrósticos y cuestionarios.

Figura 2. Arriba: Remeras elaboradas por el estudiantado para identificarse como el 'escuadrón antiAedes' y así concientizar en barrios cercanos a la escuela. Abajo: Participación en la feria de ciencias y charla informativa sobre dengue, mostrando fanzines, repelentes, pancartas, folletos, etc.

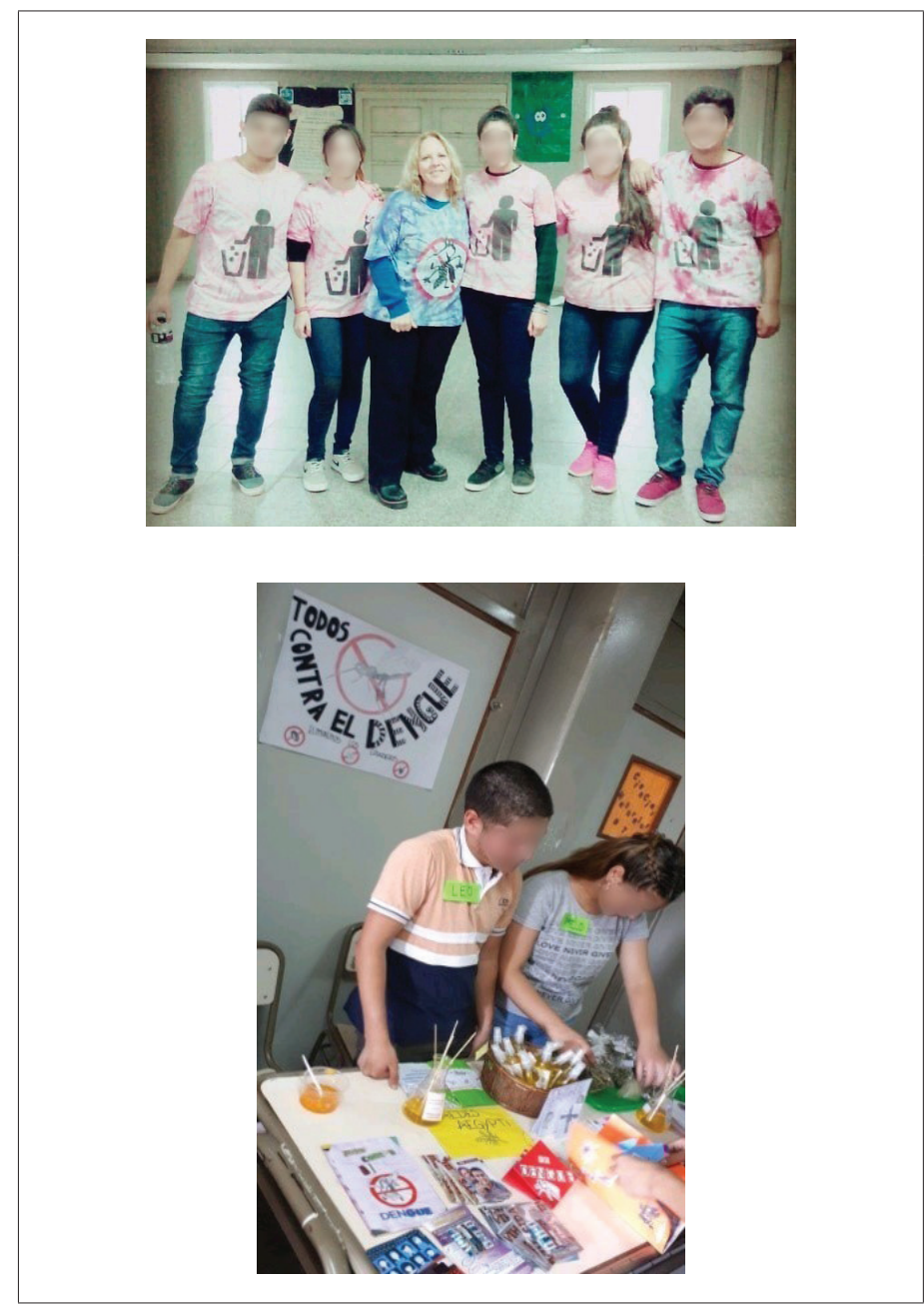

Fuente: Elaboración de los autores. Autorización y créditos de Prof. L. García (izq.).

Argumentación sobre problemáticas socio-científicas que incluyen decisiones sobre la diversidad biológica y su conservación (caso 3)

Aunque la biodiversidad definida por el Convenio sobre la Diversidad Biológica (CBD) en 1992 fue concebida en tres niveles organizativos diferentes (genético, especie y ecosistema), la comprensión actual del concepto incluye muchos 
otros componentes (BERMUDEZ; LINDEMANN-MATTHIES, 2020). La biodiversidad desempeña un papel importante en el funcionamiento del ecosistema, proporcionando bienes ambientales comunes para nuestro bienestar (IPBES, 2019). Según la Organización de las Naciones Unidas para la Educación, la Ciencia y la Cultura (UNESCO), la biodiversidad ya no puede ser un concepto que sea entendido sólo por intelectuales y conservacionistas (NACIONES UNIDAS, 2015). Por ello, enseñar y aprender sobre el concepto de biodiversidad implica desafiar los supuestos comunes y superar obstáculos cognitivos y afectivos (PÉREZ, 2013). Como estrategia para lograr lo anterior, la argumentación, entendida como la capacidad de relacionar datos y conclusiones, de evaluar enunciados teóricos a la luz de datos empíricos o razonar criterios para elegir entre opciones o refutar opiniones, ha recibido gran atención por parte de la investigación educativa (CHION et al., 2015). Para elaborar y evaluar argumentos científicos, el modelo de Stephen Toulmin representa un desafío para el estudiantado al coordinar datos con conclusiones o al utilizar criterios apropiados para evaluar la validez de una conclusión (CHAMIZO, 2007).

Implementaciones y contexto. Nos propusimos estudiar problemáticas socioambientales relacionadas con la pérdida de los componentes de la biodiversidad y los impactos sociales y ecosistémicos derivados (avance de la frontera agropecuaria, anegamiento de los suelos y pérdida de su fertilidad, expansión de especies exóticas, etc.). La experiencia fue desarrollada en 2017 en la asignatura 'Ecología' de $5^{\circ}$ año del COCN (estudiantes de 16-17 años de edad).

Actividades y tareas. Inicialmente explicitamos las concepciones alternativas y conocimientos conceptuales de la biodiversidad a través de la discusión de una nota periodística sobre la reforestación de campos con árboles exóticos, y luego de identificar los puntos de partida, buscamos aproximarnos a un modelo escolar de referencia (BERMUDEZ; DE LONGHI, 2015). Para ello, los docentes elaboramos textos recopilando, traduciendo y adaptando artículos científicos. Dado que la institución educativa se encuentra en un contexto ambiental dominado por el paisaje agrícola, realizamos un trabajo de campo a una reserva natural (Figura 3). Luego de resignificar las experiencias y saberes puestos en juego en la identificación de especies y los procesos ecosistémicos, retomamos interrogantes que orientarían la búsqueda de evidencias para la evaluación de declaraciones de conocimiento. Y con el fin de tomar decisiones sobre problemáticas sociocientíficas locales, construimos de forma progresiva argumentos según el modelo de argumentación científica de Toulmin (Figura 3). Los elementos eran las justificaciones, marco teórico, datos, conclusiones y reservas en torno a cuestiones como la pérdida de suelos, los cambios en las cuencas de ríos, etc. Tras ello, escribimos una carta dirigida a la gobernación de la Provincia y a los medios de comunicación, posicionándonos sobre dos de las temáticas conflictivas de entonces: el proyecto de ley del Plan Provincial Agroforestal ${ }^{16}$ (PPA) y los cambios propuestos en el Ordenamiento Territorial de Bosques Nativos de Córdoba ${ }^{17}$ (OTBN). 
Figura 3. Arriba: Salida de campo para el reconocimiento de especies nativas en el Jardín Botánico Gaspar Xuares, ciudad de Córdoba. Abajo: Elaboración de argumentos según el modelo de Toulmin sobre problemáticas socioambientales de la Provincia de Córdoba.

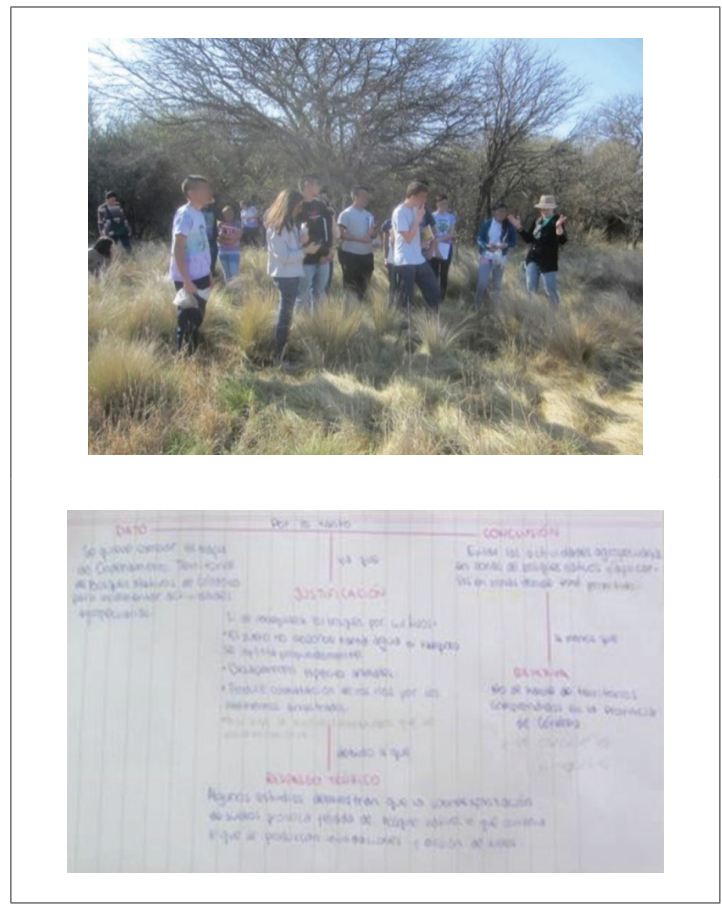

Fuente: Elaboración de los autores.

\section{INTERPRETACIONES Y REFLEXIONES SOBRE LAS PRÁCTICAS: RECONCEPTUALIZANDO UNA DIDÁCTICA CONTEXTUALIZADA Y EN EL TERRITORIO}

[...] quiero apoyar una pedagogía transformadora -enraizada en [un] proyecto de democracia renaciente e insurrecta- [...] que implacablemente cuestione el tipo de trabajo, las prácticas, y las formas de producción que se representan en la educación pública y superior. (GIROUX, 2013, p.18)

Coincidimos con Candau (1987) en que la reflexión didáctica parte del compromiso con la transformación social, por lo que enfocaremos nuestras consideraciones de la práctica educativa en función de esta perspectiva.

En relación con la pregunta de investigación 'i', el lugar que ocupan los distintos saberes en el aula ha sido motivo de discusión desde hace muchos años (PÉREZ, 2013; SASSERON, 2015). Así, hemos identificado que los casos descriptos previamente se encuentran con el desafío de cuestionar las formas tradicionales de enseñanza, en las que los saberes académicos se justifican per se, y los cotidianos se asumen como faltas o errores. Por ejemplo, en el caso 3, uno de los alcances más importantes fue la resignificación de un concepto abarcador de todos los componentes y niveles de expresión de la biodiversidad, a través del desarrollo del reconocimiento y uso de 
conocimientos sobre-y experiencias con-plantas y animales (nombres, características, etc.), recuperando tradiciones familiares y el contacto personal con la naturaleza (Figura 3). Pero para ello, primero fue necesario realizar un proceso de transposición didáctica que acerque saberes actuales y del contexto próximo al aula. En este sentido, la mayoría de las publicaciones científicas están publicadas en inglés en revistas extranjeras de pago, con lo que ocupamos un tiempo significativo en conseguirlas, traducirlas y adaptarlas de manera creativa. En el contexto de discusiones que buscaban argumentar sobre cuestiones sociocientíficas, encontramos expresiones como "yo lo veo asî", o "siempre que vi el campo había...", "en mi casa no...", "en la nota decía que un científico se oponía porque...". Estas formulaciones dan señales de que las y los estudiantes están poniendo en juego un acervo de experiencias y puntos de vista cotidianos y escolares, en el marco de prácticas epistémicas (pregunta de investigación ' $i i$ ). Aquí retomamos el concepto de conocimiento tradicional biológico, o conocimiento etnoecológico tradicional (CET), el que se ha puesto de manifiesto cuando las y los estudiantes expresan los nombres de algunas especies (caso 3, Figura 3), recuerdan prácticas de sembrado familiares (caso 1, Figura 1), o identifican fuentes de saber con lógicas distintas al conocimiento escolar (caso 2, Figura 2). En este último caso, la temática del dengue/ zika/chikungunya no siempre resultaba atractiva para el estudiantado, cuyas concepciones alternativas y conocimientos conceptuales se encuentran centrados en fundamentos biológicos superficiales y relaciones unicausales. Sin embargo, el trabajo desde nuestra perspectiva de educación en salud (caso 2) ha generado, según los relatos de las y los estudiantes, confrontaciones hogareñas cuando los saberes tradicionales y prácticas cotidianas entran en contradicción con el conocimiento escolar.

Es importante destacar que la propuesta didáctica que sostenemos y la complejidad de los entramados socioambientales reclama la distinción entre CET y conocimiento científico occidental, sin caer en reduccionismos al pretender otorgar veracidad a una episteme en detrimento de la otra, y reconociendo sus criterios de racionalidad y producción de conocimiento útil (ANDRADE; MOJICA, 2013). Además, dado que las percepciones de la importancia y conservación de especies difieren entre actores sociales (MARTÍNEZ; MANZANO-GARCÍA, 2016), es importante discutir desde distintas voces aspectos como criterios de relevancia y categorización, utilidad de taxones, prioridades de desarrollo, etc. De este modo, la HAE (caso 1) y la argumentación sobre biodiversidad (caso 3) emergieron como prácticas para el ejercicio de una ciudadanía crítica de los sistemas de valoración, uso y conocimiento del contexto socioambiental (CALDERÓN, 2012). En este sentido, adquiere mayor relevancia para la discusión de la pregunta de investigación ' $i$ ' el hecho de que una ciudad como Malvinas Argentinas haya sido un ícono para la resistencia ante las lógicas extractivistas y las presiones del poder económico. ${ }^{18}$

En relación con lo anterior, entre las líneas de trabajo sobre argumentación en la educación en ciencias (JUSTI, 2015), consideramos que hemos podido identificar obstáculos epistemológicos para esta práctica social (caso 3, preguntas de investigación ' $i$ ' y 'ii'). Por ejemplo, el hecho de que las personas tendamos a confiar de manera irreflexiva en evaluaciones originadas en experiencias cotidianas o por razonamiento de sentido común (ej. "en el campo siempre hay vacas", caso 3). Este obstáculo puede influir en el aprendizaje cuando la/el estudiante es susceptible 
de creer que sus propias capacidades epistémicas son suficientes per se para evaluar hechos o la veracidad de afirmaciones (SCHARRER et al., 2012). Más aún, esta visión dogmática sobre la propia forma de entender el mundo podría influir en que el estudiantado se vea imposibilitado de cuestionar y visibilizar el status quo y la desigualdad social. También debemos mencionar que la enseñanza habitual de las ciencias, en la que ésta se presenta como acabada y neutra, puede contribuir a que las y los educandos muestren desinterés en cuestionar las fuentes, a discutir posiciones o reconocer la historia y contexto del conocimiento escolar en construcción, ${ }^{19}$ esperando conocer y "anotar" la versión académica legitimada.

Desde una perspectiva educativa más amplia, el obstáculo, o la contracara del anterior, quizá radique en que las y los estudiantes se perciban a sí mismos como incapaces de poner a prueba declaraciones de conocimiento o posiciones sociales en general. ${ }^{20} \mathrm{Si}$ este fuera el caso, las prácticas escolares para un ejercicio democrático de una ciudadanía crítica deberían desnaturalizar con más ahínco las desigualdades socioambientales y desarmar los discursos dominantes (pregunta 'ii'). Recordemos que tras décadas de segregación social, la escuela pública argentina viene siendo un ámbito donde se ha consolidado la fragmentación educativa, pero donde también se ofrece resistencia bajo el ideario de igualdad. De hecho, al retomar la noción de pensamiento crítico, ${ }^{21}$ el conocimiento científico adquiere relevancia precisamente en problemáticas de orden socioambiental trabajados en los tres casos (los sistemas de producción agroecológicos versus industriales, las decisiones y comportamientos individuales versus comunitarios sobre salud, y el avance de la frontera agropecuaria versus protección de la biodiversidad nativa y de los bienes ambientales comunes de la naturaleza). Pensar críticamente debería interpelar al ciudadano que, desde un perfil económico desfavorable, no tiene garantizada ni la participación democrática ni el acceso equitativo a bienes de la naturaleza. A su vez, las personas han de reconocerse como receptoras de las consecuencias socioambientales de las decisiones tomadas por el poder dominante (fumigaciones con agrotóxicos en hogares rodeados de monocultivos, inundaciones por la sobreexplotación del suelo, etc.). Es decir, enseñar a pensar críticamente sobre biodiversidad, alimentación y salud excede lo biológico -si fuera posible delimitarlo-, y vuelve necesario que el profesorado cuestione el status quo de las dimensiones político-sociales e individuales que atraviesan las problemáticas (pregunta de investigación 'ii').

Lo anterior incluye tanto a las políticas nacionales como a las institucionales (pregunta 'iii), puesto que desarrollar de forma sostenida la HAE como estrategia de enseñanza (caso 1) no ha sido tarea sencilla por la falta de apoyo de las distintas gestiones escolares (ALLIAUD; VEZUB, 2012). Al respecto, Edelstein (2011) apunta que "La enseñanza es compleja dado que se desarrolla en escenarios singulares, bordeados y surcados por el contexto. Los múltiples determinantes que la atraviesan impactan sensiblemente en la tarea cotidiana; ello hace que esté sometida a tensiones y contradicciones [...]” (p. 105). En este caso, ello repercutió en incidentes críticos (ANIJOVICH; CAPELLETTI, 2018) como el traslado reiterado de la HAE a distintos sectores del patio como en la imposibilidad de dirigir recursos para, por ejemplo, cercarla, y así cuidar las cosechas, que, en ocasiones, eran saqueadas durante los fines de semana. A pesar de ello, el estudiantado siempre renovó su motivación para continuar con la huerta, aunque haya significado a veces 
"empezar desde cero" (pregunta iii). También, al comenzar el año lectivo, y gracias a los relatos de las vivencias de familiares y amistades, las y los estudiantes piden por la HAE. En cuanto a las políticas externas que inciden en el caso, el Instituto Nacional de Tecnología Agropecuaria de Argentina (INTA) tuvo hace unos años un conjunto nutrido de programas (ProHuerta), ${ }^{22}$ destinado a la promoción de prácticas productivas agroecológicas para el autoabastecimiento y la educación alimentaria. Sin embargo, estas acciones sufrieron un grave desfinanciamiento de 2017 a fines de 2019, con lo que se hizo dificultoso el acceso a semillas de calidad. ${ }^{23}$ A pesar de estos obstáculos, la HAE ha logrado consolidarse como proyecto educativo institucional, y tiene como desafío ofrecer múltiples posibilidades para situar a los procesos de enseñanza y aprendizaje. Por ejemplo, la HAE ha permitido integrar ciclos y procesos ecológicos, la dinámica de los fenómenos naturales y las relaciones entre los elementos que componen el ecosistema. Esta estrategia también ha posibilitado el abordaje de problemas reales que se originan, concretan y reformulan en los contextos específicos de la vida cotidiana del estudiantado, como el avance de la frontera agropecuaria, la soberanía alimentaria, las condiciones socio-económicas y los estilos de vida actuales, etc., siguiendo la expresión 'piensa globalmente, actúa localmente'.

En relación con la pregunta de investigación 'iii', y con base en una perspectiva crítica del currículum (DE ALBA, 2006), pudimos identificar que, para el caso 3 , los diseños curriculares ${ }^{24}$ reconocen una perspectiva multidimensional de la biodiversidad en la asignatura 'Ecología' (EOI). ${ }^{25}$ En cambio, en asignaturas obligatorias en el Ciclo Básico y comunes a todas las orientaciones de la educación secundaria (como Biología), los lineamientos curriculares y manuales escolares tratan la diversidad biológica desde lo taxonómico y clasificatorio (BERMUDEZ; DE LONGHI, 2015). Ello incide en que la enseñanza de la biodiversidad se enriquezca de connotaciones biologicistas y utilitaristas sobre su existencia y conservación (BERMUDEZ et al., 2015). Pero, principalmente, esta perspectiva economicista y organísmica no alcanza a visibilizar la concentración en pocas manos y con réditos máximos a corto plazo de los beneficios de la naturaleza para las personas, ${ }^{26}$ como tampoco a ofrecer medios para las situaciones en las que el ejercicio de una ciudadanía plena va más allá de conocer la fecha y lugar de la firma del CBD. En este sentido, Baguer y Jericó (2017) señalan que el impacto en el ambiente reclama que "conocer" no debería ser una capacidad intelectual ciega al valor de lo conocido, sino que también debe ser un principio transformador de la persona. Una didáctica en el territorio persigue una ética del valor asociado al conocimiento, un valor que se aprende a descubrir en la realidad desde el mismo momento de conocerla. Así, en el caso 3, parte de las actividades en la salida de campo (Figura 3) estaban destinadas a la percepción del ambiente y la sensibilización hacia sus características (GARCÍA; BERMUDEZ, 2019). También, la construcción de la huerta y elaboración de alimentos a partir de ella (caso 1) acerca una variedad de plantas a la mesa de las y los estudiantes, promueve el contacto directo a través de cualidades sensoriales y el conocimiento se vuelve palpable, se materializa. De hecho, las y los estudiantes de varias cohortes han manifestado haber probado por primera vez los vegetales cosechados en la HAE, o que antes les habían disgustado, pero que a partir de la elaboración de alimentos con ellos pensaban seguir consumiéndolos. Además, la HAE se convierte en un 
terreno simbólico y de encuentro para el aprendizaje colaborativo y el desarrollo de la paciencia, autoestima y sentido de pertenencia.

Coincidimos con Giroux (2013) en que los educadores necesitamos "lanzar una mirada crítica a [los conocimientos] y relaciones sociales que los definen a través de una pureza conceptual y una inocencia política que oculta el hecho de que la presunta neutralidad sobre la que se apoyan ya está basada en elecciones éticas y políticas" (p. 18). Por ello, los casos trabajados dan cuenta que los materiales curriculares están impregnados de las problemáticas socioambientales del territorio ${ }^{27}$ (preguntas de investigación 'ii' y ' $i i i$ ). En ese sentido, las propuestas didácticas ponen en tensión la desigualdad social dada por la apropiación y uso indiscriminado de los bienes ambientales comunes y las consecuencias derivadas de la disparidad en los beneficios y perjuicios de los distintos sectores de la sociedad, la toma de decisiones sobre el uso público y privado de tales bienes, el enmascaramiento y tergiversación de los espacios jurídicos de participación ciudadana (consultas populares, etc.), el valor de los saberes y argumentos aportados como verdades incuestionables (tales como el desarrollo o la integración regional), tanto como sus evidencias y pruebas de legitimidad (estudios de impacto, etc.) (caso 3).

Coincidiendo con De Alba (2006) acerca de la necesidad de repensar el curriculum con perspectiva de "resistencia y lucha social, [centrado en una] óptica de análisis centrado en la vida cotidiana" (p.57), el tránsito por la enseñanza de las problemáticas de salud (caso 2) también marca el rumbo para no sólo encontrar los intersticios curriculares (FRIGERIO, 1991) sino, más bien, de desenredar esta trama (pregunta de investigación 'iii). Con ello nos referimos a que la separata de los diseños curriculares de la asignatura 'Educación para la Salud' establece como uno de los aprendizajes la "identificación de las epidemias, endemias y pandemias históricas más relevantes; causas, impacto y acciones realizadas para combatirlas, en particular las actuales y las que afectan a nuestra región. Por ejemplo, los casos de la peste negra, el cólera, VIH-SIDA [...]” (MEPC, 2017, p.15), cuando la peste negra ya no representa una enfermedad actual en nuestros países. Así, la enseñanza desde el territorio reclama el des-entramado de contenidos atávicos, que, como la peste negra, el sistema reproductor, etc., persisten en los diseños de manera estática y descontextualizada. De manera similar, el huerto escolar (aunque no de tipo agroecológico) es citado como ejemplo para el diseño y gestión de un proyecto tecnológico, tanto como un terrario y un periódico, en el apartado 'Orientaciones para la enseñanza' de la asignatura 'Formación para la vida y el trabajo’ (3ªño del Ciclo Básico) (MEPC, 2011, p.173). Sin embargo, no figura para ninguna otra materia ni para este ciclo ni para el COCN.

En cuanto a la pregunta de investigación ' iv', el caso 2 es especialmente significativo en tanto que, con el paso de los años, las acciones en salud desarrolladas son cada vez más demandadas por entidades de la localidad, tales como otras escuelas, cooperativas de servicios y la radio local. Sin embargo, las implementaciones tienen lugar generalmente a contra turno, con lo que el estudiantado dedica tiempo extraescolar, mientras que los docentes podemos estar imposibilitados de acompañar las actividades al tener que responder a otras obligaciones laborales. A pesar de ello, a través de una progresión en la adquisición de autonomía y el trabajo colaborativo, el estudiantado lleva a cabo las intervenciones apoyándose mutuamente y en responsables de los entes receptores. A través de la experiencia podemos dar cuenta 
de aprendizajes y cambios en los comportamientos y actitudes del estudiantado no sólo sobre dengue/chikungunya/zika sino, también, en cuanto al autoestima, competencia comunicacional y desarrollo socioafectivo. Las acciones para la intervención en la comunidad, y la búsqueda de una transformación social, también se plasmaron en los casos 1 y 3 . En cuanto al primero, las huertas domiciliarias continúan ofreciendo aproximaciones no convencionales de cultivo a los vecinos de Malvinas Argentinas, además de propiciar ventajas para la economía familiar. En el segundo caso, luego de la revisión y discusión de los argumentos esgrimidos por cada grupo en la carta a la gobernación, los docentes compaginamos una nueva nota, con los aportes de toda la clase, para que sea circulada en diferentes medios y soportes. También remitimos para su publicación la versión final de la carta a diarios y portales de noticias de Córdoba, pero de manera infructuosa, puesto que nunca fue publicada. Sin embargo, los aprendizajes continuaban dando fruto en las fotografías de plantas y animales que las y los estudiantes seguían identificando y nos enviaban, una vez terminado el año lectivo, y de los plantines de especies nativas que producían para reforestar.

Por último, queremos dar cuenta que nuestra postura didáctica asume un importante nivel de involucramiento del profesorado para orientar la enseñanza hacia aprendizajes significativos y con sentido, que permitan al estudiantado resolver problemas de la vida real y constituyan la base de un aprendizaje durante toda la vida (CAMILLONI, 2015). Con ello, en este trabajo hemos dado cuenta de la puesta en marcha de dispositivos didácticos en los que la alfabetización científica está al servicio de la construcción de una ciudadanía crítica de las posiciones dominantes y de sus impactos sociales. Y para ello, la necesidad de cuestionar discursos hegemónicos que reducen la expresión de la ciudadanía al comportamiento individual y futuro, para implicar, en cambio, a las y los jóvenes en contextos cercanos y actividades cotidianas que persigan la transformación social. Sin embargo, creemos que una formación emancipadora del modelo socioambiental actual reclama de experiencias más profundas y sistemáticas que las llevadas a cabo por este grupo.

Lo anterior también interpela a las y los profesores a concebir con un renovado compromiso el desarrollo profesional. La idea del profesor como técnico o ejecutor de proyectos externamente elaborados fue sustituida hace tiempo por la del "docente como colaborador en la implementación de los procesos de reforma, intérprete y agente curricular, profesional que redefine o reconstruye el proyecto curricular [...]" (COLS, 2015, p.113). Sin embargo, esta identidad profesional requiere de la observación, análisis, crítica y reflexión sobre la práctica diaria si ésta pretende ser innovadora, lo que, a su vez, ubica al profesor en un diálogo con pares. La tarea no es sencilla frente al sinnúmero de impedimentos y contradicciones que caracterizan en la actualidad la vida en las aulas (ANIJOVICH; CAPELLETTTI, 2018). Aun así, ser capaces de incidir en transformaciones educativas en contextos con distinto tipo y grado de vulnerabilidad forma parte de la profesionalidad y del oficio del docente. Queda pendiente para la Didáctica encauzar las vías para que la práctica y la investigación generen propuestas formativas y materiales probados en los que la enseñanza y el aprendizaje de la Biología y de las Ciencias Naturales estén cada vez más ligados a alcanzar una ciudadanía más democrática e igualitaria en lo social y ambiental. 


\section{REFERENCIAS BIBLIOGRÁFICAS}

ALEIXANDRE, M. P. Diez ideas clave: competencias en argumentación y uso de pruebas. Barcelona: Graó, 2010.

ALLIAUD, A. Los artesanos de la enseñanza. Acerca de la formación de maestros con oficio. Buenos Aires: PAIDÓS, 2017.

ALLIAUD, A.; VEZUB, L. El oficio de enseñar: sobre el quehacer, el saber y el sentir de los docentes argentinos. Revista Diálogo Educacional, Curitiba, v. 12, n. 37, p. 927-952, 2012.

ALTIERI, M. A.; NICHOLLS, C. I. Conversión agroecológica de sistemas convencionales de producción: teoría, estrategias y evaluación. Ecosistemas, Revista Científica y Técnica de Ecología y Medio Ambiente, v. 16, n. 1, p. 3-12, enero 2007.

ANDRADE MOLINA, A.; MOJICA, L. Enseñanza como puente entre conocimientos científicos escolares y conocimientos ecológicos tradicionales. Magis, Revista Internacional de Investigación en Educación, v. 6, n. 12, p. 37-53, 2013.

ANIJOVICH, R.; CAPELLETTI, G. La práctica reflexiva en los docentes en servicio. Posibilidades y limitaciones. Espacios en Blanco. Revista de Educación, Tandil, n. 28, p.74-92, 2018.

ARROYO, M. Educação e exclusão da cidadania. En BUFFA, E., ARROYO, M. y NOSELLA, P. São Paulo: Cortez, 2010.

BAGUER PUIG, J.; JERICÓ CASAS, M. El impacto ambiental: un despertar ético valioso para la educación. Teoría de la Educación. Revista Interuniversitaria, Salamanca, v. 29, n. 1, p. 101-128, enero/junio 2017.

BENEDICTO, J. y MORÁN, M. L. Aprendiendo a ser ciudadanos. Experiencias sociales y construcción de la ciudadanía entre los jóvenes. Madrid: INJUVE Editor, 2003.

BERMUDEZ, G. M.A.; DE LONGHI, A. L. Retos para la enseñanza de la biodiversidad hoy. Aportes para la formación docente. Córdoba: Editorial de la Universidad Nacional de Córdoba, 2015. Disponible en: https://www.researchgate.net/publication/283256837_Retos_para_la_ensenanza_de_ la_biodiversidad_hoy_Aportes_para_la_formacion_docente. Último acceso en: 23 ago. 2020.

BERMUDEZ, G. M.A.; DE LONGHI, A. L.; GAVIDIA, V. La enseñanza monumentalista y utilitarista de las causas de la biodiversidad y de las estrategias para su conservación. Un estudio sobre la transposición didáctica de los manuales de la Educación Secundaria española. Ciência \& Educação, Bauru, v. 21, n. 3, p. 17-34, 2015. Disponible en: https://doi.org/10.1590/1516731320150030010. Último acceso en: 23 ago. 2020.

BERMUDEZ, G. M.A.; LINDEMANN-MATTHIES, P. "What matters is species richness"high school students' understanding of the components of biodiversity. Research in Science Education, Dordrecht, v. 50, n. 6, p. 2159-2187, 2020. Disponible en: https://doi.org/10.1007/ s11165-018-9767-y. Último acceso en: 23 ago. 2020.

BRASLAVSKY, C. La discriminación educativa en Argentina. Buenos Aires: Miño y Dávila, 1989.

CAMILLONI, A. Los profesores y el saber didáctico. En: CAMILLONI, A. de; COLS, E.; BESABE, L.; FEENEY, S. El saber didáctico. Buenos Aires: Paidós, 2015, p. 41-60.

CANDAU, V. M. La Didáctica en cuestión. Investigación y Enseñanza. Madrid: Narcea Editor, 1987. 
CEBAllos, M. Aprovechamiento didáctico de los huertos escolares en centros de Sevilla. Enseñanza de las ciencias, Sevilla, n. extra congreso, p. 787-792, 2017.

CERVINI I., R. A. The relationship between school composition, school process and mathematics achievement in secondary education in Argentina. International Review of Education, Ámsterdam, v. 51, n. 2-3, p. 173-200, mayo 2005.

CERVINI, R. Los efectos de la escuela y del aula sobre el logro en matemáticas y en lengua de la educación secundaria: Un modelo multinivel. Perfiles Educativos, México, n. 28, p. 68-97, enero 2006.

CHAMIZO GUERRERO, J. A. Las aportaciones de Toulmin a la enseñanza de las ciencias. Enseñanza de las Ciencias, Barcelona, v. 25, n. 1, p. 133-146, 2007.

CHEVAlLARD, Ys. La Transposición Didáctica. Del saber sabio al saber enseñado. Buenos Aires: Aique, 1991.

CHION REVEL, A.; MEINARDI, E.; ADÚRIZ-BRAVO, A. La argumentación científica escolar: contribución a la comprensión de un modelo complejo de salud y enfermedad. Ciência \& Educação, Bauru, v. 20, n. 4, p. 987-1001, octubre/diciembre 2014.

CISTERNA, F. C. Categorización y triangulación como procesos de validación del conocimiento en investigación cualitativa. Theoria, Chillán, v. 14, n. 1, p. 61-71, 2005.

COLS, E. "Problemas de la enseñanza y propuestas didácticas a través del tiempo”. En: CAMILLONI, A., COLS, E., BASABE, L., FEENEY, S. (ed.). El saber didáctico. Buenos Aires: Paidós, 2015, p. 71-124.

CORA, G. D.; RODRÍGUEZ, M. Construyendo la "Nueva Argentina". Cultura Ciudadana y la consolidación de la política educativa del peronismo (1952-1955). Espacio, Tiempo y Educación, Salamanca, v. 1, n. 2, p. 187-205, 2015.

CORDERO, S.; DUMRAUF, A.; MENGASCINI, A.; SANMARTINO, M. Entre la Didáctica de las Ciencias Naturales y la Educación Popular en Ciencias Naturales, Ambiente y Salud: relatos y reflexiones de un camino en construcción. Praxis Educativa, La Pampa, v. 15, p. 71-79, marzo 2011 - febrero 2012.

DE ALBA, A. Curriculum: crisis, mito y perspectiva. Editorial: Miño y Dávila, Buenos Aires, Argentina, 2006.

DÍAZ BARRIGA, Á. Pensar la didáctica. Editorial: Amorrortu, Buenos Aires, Argentina, 2009.

DO NASCIMENTO BORBA, R.; DE ANDRADE PIRES, M. C.; SELLES ESCOVEDO, S. Ensino de ciências e biologia e o cenário de restauração conservadora no Brasil: inquietações e reflexões. Revista Interinstitucional Artes de Educar, Rio de Janeiro, v. 5, n. 2, p.144-162, 2019.

DUBET, F. Mutaciones cruzadas: la ciudadanía y la escuela. En: Benedicto, J. y M. Morán (Coord.), Aprendiendo a ser ciudadanos. Experiencias sociales y construcción de la ciudadanía entre los jóvenes. Madrid: Instituto de la Juventud, 2003, p. 219-234.

EDELSTEIN, G. Formar y formarse en la enseñanza. Editorial: Paidós, Buenos Aires, 2011.

FELDMAN, D. Dos problemas actuales para la didáctica. Revista de Educación, Mar del Plata, v. 14, n. 2, p. 129-146, 2018.

FREIRE, P. Pedagogia da tolerância. Editorial: Unesp, São Paulo, 2004. 
FRIGERIO, G. Currículum: norma, intersticios, transposición didáctica y textos. En: FRIGERIO, G. et al. Currículum presente, ciencia ausente. Normas, teorías y críticas. Buenos Aires: Miño y Dávila, 1991, p.15-53.

GARCÍA, L. P.; BERMUDEZ, G. M.A. Salidas de campo para la enseñanza de la biodiversidad. Una oportunidad para incentivar el conocimiento y valoración del medio ambiente. En: XIII JORNADAS NACIONALES Y VIII CONGRESO INTERNACIONAL EN ENSEÑANZA DE LA BIOLOGÍA, 2018, Quilmes. Revista de Educación en Biología, Córdoba, n. extraordinario, p. 555-563. Disponible en: http://congresos.adbia.org.ar/index.php/congresos/article/view/408. Último acceso en: 23 ago. 2020.

GARELLI, Fernando; SANMARTINO, Mariana; DUMRAUF, Ana. Análisis de materiales didácticos e informativos sobre dengue en Argentina. Interface (Botucatu), Botucatu, v. 21, n. 60, p. 35-49, 2017. Disponible en http://www.scielo.br/scielo.php?script=sci_arttext\&pid=S1414$32832017000100035 \& \operatorname{lng}=$ en\&nrm=iso. Último acceso en: 23 ago. 2020.

GESSAGHI, V. La educación privada y las experiencias formativas de la clase alta en la Argentina. Educação e Pesquisa, São Paulo, v. 43, n. 4, p. 973-986, 2017.

GIROUX, H. La pedagogía crítica en tiempos oscuros de Henry Giroux. Praxis Educativa, La Pampa, v. 17, n. 2, p. 13-26, enero/diciembre 2013.

GONZÁLEZ-HOWARD, M.; MCNEILL, K. L. Acting with epistemic agency: Characterizing student critique during argumentation discussions. Science Education, en prensa, 2020. Disponible en: https://doi.org/10.1002/sce.21592. Último acceso en: 23 ago. 2020.

IPBES. Summary for policymakers of the global assessment report on biodiversity and ecosystem services of the Intergovernmental Science-Policy Platform on Biodiversity and Ecosystem Services. Advance unedited version. 6 May 2019. Bonn: IPBES secretariat, Germany, 2019.

JUSTI, R. Relações entre argumentação e modelagem no contexto da ciência e do ensino de ciência. Ensaio Pesquisa em Educação em Ciências, Belo Horizonte, Brasil, v. 17, p. 31-48, 2015.

KEMMIS, S.; MCTAGGART, R. Cómo planificar la investigación-acción. Editorial: Laertes, Barcelona, 1988.

LATORRE, A.; DEL RINCÓN IGEA, D.; ARNAL, J. Bases metodológicas de la investigación educativa. Editorial: Experiencia, Barcelona, 2005.

LEVINSON, R. Science education and democratic participation: An uneasy congruence? Studies in Science Education, v. 46, n. 1, p. 69-119, febrero 2010.

LITWIN, E. "El oficio del docente en el borde del curriculum". En: LITWIN, E. El oficio de enseñar. Condiciones y contextos. Buenos Aires: Paidós, 2008, p. 117-139.

LOCATELLI, R. La educación como bien público y común. Reformular la gobernanza de la educación en un contexto cambiante. Perfiles Educativos, México, v. 40, n. 162, p. 178-196, octubre/diciembre 2018.

LÓPEZ-MOTA, Á.; MORENO-ARCURI, G. Sustentación teórica y descripción metodológica del proceso de obtención de criterios de diseño y validación para secuencias didácticas basadas en modelos: el caso del fenómeno de fermentación. Bio-grafía: Escritos sobre la biología y su enseñanza, Bogotá, v. 7, n. 13, p. 109-126, 2014. 
LÓPEZ VILCHES, J. E.; BENAVIDES ESCOBAR, T. Uso de laboratorio, huerto escolar y visitas a centros de naturaleza en Primaria: Percepción de los futuros maestros durante sus prácticas docentes. Revista Electrónica de Enseñanza de las Ciencias, Vigo, v. 13, n. 2, p. 222-241, 2014.

LUDUEÑA, M. E. Malvinas Argentinas, el pueblo cordobés que venció a Monsanto. Chequeado. Buenos Aires, 29 mar. 2017. Disponible en: https://www.chequeado.com/investigacion/ malvinas-argentinas-el-pueblo-cordobes-que-vencio-a-monsanto/. Último acceso en: 23 ago. 2020.

MARTÍNEZ, G.; MANZANO-GARCÍA, J. Estilos de percepción de la biodiversidad y su conservación en actores sociales de áreas protegidas de Córdoba. Revista del Museo de Antropología, Córdoba, v. 9, n. 2, p. 135-152, 2016.

MARTÍNEZ, R., TRUCCO, D. y PALMA, A. El analfabetismo funcional en América Latina y el Caribe. Panorama y principales desafíos de política. Serie Políticas sociales CEPAL. Santiago de Chile: Naciones Unidas, 2014.

MASSARINI, A.; SCHNEK, A. Ciencia entre todxs. Tecnociencia en contexto social. Una propuesta de enseñanza. Buenos Aires: Paidós, 2015.

MÉHEUT, M.; PSILLOS, D. Teaching-learning sequences: aims and tools for science education research. International Journal of Science Education, Londres, v. 26, n. 5, p. 515-535, 2007.

MEINARDI, E. Alfabetización científica: más allá del dominio de los códigos y de las competencias de leer y escribir. Revista de Educación en Biología, Córdoba, v.19, n. 2, p. 78-84, 2016.

MEINARDI, E. La investigación didáctica y el compromiso con el desarrollo Profesional docente para lograr una alfabetización científica de calidad en escuela inclusivas. Buenos Aires: Universidad de Buenos Aires, 2008. Disponible en: http://2007-2016.exactas.uba.ar/ download.php?id=734. Último acceso en 9 dic. 2019.

MEPC. Separata Orientación Ciencias Naturales. Espacios de Opción Institucional. Aprendizajes sugeridos. Secretaría de Educación, Córdoba, Argentina, 2017.

MEPC. Ciclo Básico de la Educación Secundaria (Versión definitiva 2011-2020). Tomo 2. Secretaría de Educación, Córdoba, Argentina, 2011.

NARODOWSKI, M.; GOTTAU, V. Clases medias y escuela pública. La elección escolar como resistencia. Perfiles Educativos, México, v. 39, n. 157, p. 34-51, julio/septiembre 2017.

OECD. PISA 2009 results: Overcoming social background - Equity in learning opportunities and outcomes, v. 2, París, Francia 2010 b. Disponible en: http://dx.doi.org/10.1787/9789264091504-en. Último acceso en: 9 dic. 2019.

OECD. PISA 2009 results: What makes a school successful? - Resources, policies and practices, v. 4. París, Francia 2010 a. Disponible en: http://dx.doi.org/10.1787/9789264091559-en. Último acceso en: 9 dic. 2019.

OSORIO, C. y MARTINS, I.. La educación científica y tecnológica para el Espacio Iberoamericano de Conocimiento. En: ALBORNOZ, M. y LÓPEZ, J. A. Ciencia, tecnología y universidad en Iberoamérica Ciencia, tecnología y universidad en Iberoamérica. Buenos Aires: Eudeba, 2010, p. 121-143.

PÉREZ, R. M. La Biodiversidad en el contexto Educativo. Múltiples miradas en el escenario mundial. Nodos y Nudos, Bogotá, v. 4, n. 35, p. 63-75, 2013. 
PÉREZ CALDERON, O. L. La huerta urbana como un laboratorio para la aplicación del concepto de ecosistema y el desarrollo de habilidades cognitivas en estudiantes de ciclo dos. Tesis doctoral. Universidad Nacional de Colombia, 2012.

PERISSÉ, A. H. La ciudadanía como construcción histórico-social y sus transformaciones en la Argentina contemporánea. Nómadas. Critical Journal of Social and Juridical Sciences, Roma, v. 26, n. 2, 2010.

PINHÃO, F.; MARTINS, I. Cidadania e ensino de ciências: questões para o debate. Ensaio Pesquisa em Educação em Ciências, Belo Horizonte, vol. 18, n. 3, p. 9-29, septiembre/diciembre 2016.

PUIGGRÓS, A. De Simón Rodríguez a Paulo Freire: educación para la integración iberoamericana. Editora: Convenio Andrés Bello, Bogotá, Colombia, 2005.

RAMOS, F. J. Educación y ciudadanía: la necesidad de generar espacios para la discrepancia y el diálogo. Foro de Educación, Salamanca, v. 14, n.20, p. 13-19, enero/junio 2016.

RIVAROSA, A.; DE LONGHI, A. L. Aportes didácticos para nociones complejas en Biología: la alimentación. Buenos Aires: Miño y Dávila, 2012.

RUIZ BARRÓN, Á.; RODRÍGUEZ MUÑOZ, J. M. Los huertos escolares comunitarios: fraguando espacios socioeducativos en y para la sostenibilidad. Foro de Educación, Salamanca, España v.13, n. 19, p. 213-239, julio/diciembre 2015.

SASSERON, L. H. Alfabetização científica, ensino por investigação e argumentação: relações entre ciências da natureza e escola. Ensaio Pesquisa em Educação em Ciências, Belo Horizonte, v. 17, p. 49-67, noviembre 2015.

SCHARRER, L.; BROMME, R.; BRITT, A.; STADTLER, M. The seduction of easiness: How science depictions influence laypeople's reliance on their own evaluation of scientific information. Learning and Instruction, v. 22, n. 3, p. 231-243, february/november 2012.

SELLES ESCOVEDO, S.; ANDRADE, P. Políticas curriculares e subalternização do trabalho docente. Editorial: Educação em Foco, Belo Horizonte, v. 21, n. 1, p. 39-64, marzo/junio 2016.

SMINK, V. Malvinas Argentinas, la comunidad que logró frenar a Monsanto, el gigante de los transgénicos. BBC Mundo. Buenos Aires, 12 dic. 2014. Disponible en:https://www.bbc.com/mundo/ noticias/2014/12/141128_argentina_transgenicos_monsanto_vs. Último acceso en: 23 ago. 2020.

TARANTO, P. Vía libre para que mineras y agroquímicas generen contenidos educativos. Tiempo Argentino, Buenos Aires, 2 jul. 2017. Disponible en: https://www.tiempoar.com.ar/nota/via-librepara-que-mineras-y-agroquimicas-generen-contenidos-educativos. Último acceso en: 23 ago. 2020.

TEDESCO, J. C. Educación y desigualdad en América Latina y el Caribe. Aportes para la agenda post 2015. Perfiles Educativos, v. 39, n. 158, p. 206-224, 2017.

TIRAMONTI, G. La trama de la desigualdad educativa. Buenos Aires: Manantial, 2004.

TIRAMONTI, G. La trama de la desigualdad educativa. Diálogos Pedagógicos, Córdoba, v. 3, n. 5, p. 94-110, abril 2005.

United Nation. YouthXchange guidebook series: biodiversity and lifestyles. UNEP Job\# DTI/1659/PA. United Nations Environment Programme (UNEP) and United Nations Educational, Scientific and Cultural Organization (UNESCO), 2012. 
VELEDA, C. La segregación educativa. Entre la fragmentación de las clases medias y la regulación atomizada. Buenos Aires: La Crujía Ediciones, 2012.

VILELA LIMA, M.; SELLES ESCOVEDO, S. Corpo Humano e Saúde nos currículos escolares: quando as abordagens socioculturais interpelam a hegemonia biomédica e higienista. Bio-grafía: Escritos sobre la biología y su enseñanza, Bogotá, v. 8, n. 15, p. 113-121, julio/diciembre 2015.

\section{CONTRIBUCIONES DE LOS AUTORES}

Los tres autores desarrollaron las experiencias, aunque la huerta y los proyectos socio-comunitarios fueron iniciados y sostenidos por la segunda autora. El proceso de sistematización y reflexión didáctica estuvo dirigido por el primer autor, tanto como la escritura del artículo, pero los tres autores contribuyeron a lo largo de todo el proceso.

\section{NOTAS}

1 La asignatura, a poco de producirse el golpe que derrocaría a Perón en 1955, y debido a que fuera advertida como vehículo de la doctrina peronista, cambió luego su nombre a "Educación Democrática".

2 En la "Noche de los Lápices" (16 de septiembre de 1976), las fuerzas estatales secuestraron y asesinaron a estudiantes secundarios de la ciudad de La Plata. La Comisión Nacional sobre la Desaparición de Personas, creada por el presidente Raúl Alfonsín, denunció que las acciones policiales de la trágica noche tuvieron el firme propósito de amedrentar la expresión de ciudadanía en que la luchaba por un boleto estudiantil. Disponible en: http://atom.ippdh.mercosur.int/index.php/conadepcomision-nacional-sobre-la-desaparicion-de-personas. Último acceso en: 9 de diciembre 2019.

3 En marzo de 2018, el entonces presidente argentino M. Macri (2015-2019) expresó en una conferencia de prensa que "hay una [...] inequidad, entre aquel que puede ir a una escuela privada y el que tiene que caer en la escuela pública". Esto generó una ola de repudios dado el desprestigio a la educación pública y el aumento del conflicto salarial docente. Disponible en: https://www.pagina12. com.ar/27018-caer-en-la-educacion-publica. Último acceso en: 9 de dic. 2019.

4 El sector privado parecía garantizar el tránsito entre niveles del sistema educativo, especialmente del secundario al universitario. Ello generó un mercado de ofertas de preparación para los exámenes de ingreso al nivel medio y terciario (BRASLAVSKY, 1989).

5 Representada en expresiones que aún se escuchan como ecos de un pasado argentino reciente: "algo habrán hecho", "sálvese quien pueda" y "no te metás".

6 Mientras los sectores sociales de ingresos medios y altos optaban por las escuelas privadas (que incrementaron fuertemente su matrícula), abandonando así la escuela pública, en el ámbito de estas últimas prevalecieron los sectores más empobrecidos (NARODOWSKI; GOTTAU, 2017).

7 Su atractivo, según Gessaghi (2017), radicaría en su éxito para garantizar un requisito fundamental para la reproducción de la clase más alta: la sociabilidad entre pares para ocupar puestos de poder.

8 Si bien este programa compara los desempeños de los estudiantes de numerosos países en relación a ciertos estándares (lo que es cuestionable en términos de heterogeneidad cultural, distribución de riqueza, etc.), sólo nos centraremos en los resultados hacia adentro de Argentina. 
9 En lo estatal el estudiante es, ante todo, un ciudadano que se forma defendiendo el interés colectivo, el espíritu crítico y el compromiso político y social (NARODOWSKI; GOTTAU, 2017).

10 Fundamental en el sentido en el que Candau (1987) refiere a una didáctica fundamental.

11 En sus propias palabras, la autora sostiene que el "currículum de borde puede ser interesante para los estudiantes pero no debería ser la única opción del docente [...] mientras que el tema de borde es aquél que no es importante o central en un campo de conocimiento" (LITWIN, 2008, p.40).

12 Y, por lo tanto, no envejecidos moral ni biológicamente (CHEVALLARD, 1991).

13 Además de asociaciones favorables y desfavorables del cultivo, rotaciones, control orgánico de plagas y enfermedades, tipos de abonos (verdes, compostaje y lombricultura), etc.

14 Procedimientos básicos de preparación del terreno, camas biointensivas con la técnica de doble excavación, siembra directa y en almácigos, repique de plantines a cantero definitivo.

15 Marcado de cercos de cada bancal, riego y aporte de cobertura vegetal (mulch).

16 Aprobado como Ley 10.467, el Plan Provincial Agroforestal establece que los campos productivos deben tener como mínimo un dos por ciento de su superficie "con cobertura vegetal arbórea o de forestación”, entre las que figuran exóticas invasoras de interés maderero.

17 Expediente 20811. Se pretende incrementar las zonas de bosques nativos que pueden ser usadas para actividades agropecuarias en áreas antes denominadas rojas (donde esto estaba prohibido) o amarillas (donde estaba estrictamente regulado).

18 Muchas de las y los estudiantes fueron partícipes de las campañas suscitadas y acciones desde la asignatura cuando una de las más grandes empresas biotecnológicas del mundo iba a instalarse en la localidad (LUDUEÑA, 2017; SMINK, 2014).

19 Por ejemplo, para elaborar los esquemas de argumentación de Toulmin (Figura 3), el estudiantado debía identificar la fuente de los datos y evaluar los tipos de justificaciones y marco teórico pertinente. En este sentido, para tomar una decisión y concluir sobre la cuestión analizada debía seleccionarse conocimiento científico pertinente, reconocer las inconsistencias de los discursos jurídicos que se sostenían desde sectores políticos, cuestionar la posición de distintos actores sociales, etc.

20 En contraposición, la agencia epistémica en prácticas argumentativas requiere que todos se vean dignos de -y sobre quienes se espera logren- contribuir a la construcción del conocimiento, a través del cuestionamiento, formulación y crítica de ideas propuestas por otros (GONZÁLEZ-HOWARD; MCNEILL, 2020). En nuestro caso, fueron muy pocos los estudiantes que actuaban en el aula con esta lógica.

21 Entendido como la capacidad de reflexión acerca de y la intervención en dilemas sociales que demandan decisiones políticas, institucionales o personales (ALEIXANDRE, 2010). Así, la promoción del pensamiento crítico permite "sentar las bases que permitan cuestionar la neutralidad de la ciencia y la tecnología y comprender el papel que desempeñan los desarrollos tecnocientíficos actuales en nuestras sociedades" (MASSARINI; SCHNEK, 2015, p.77).

22 INTA. Disponible en: https://inta.gob.ar/documentos/prohuerta. Último acceso: 15/11/19.

23 En el contexto del gobierno neoliberal de M. Macri (2015-2019), los grandes consorcios mineros y biotecnológicos (lobby agrario) lograron participar de la creación de contenidos y materiales curriculares que, legitimando modelos económicos extractivistas, naturalizan el uso de organismos genéticamente modificados y de agroquímicos (TARANTO, 2017). 
24 En el marco de la Ley 26.206 y el establecimiento de Núcleos de Aprendizaje Prioritario. Estos últimos procuran asegurar la unidad del sistema educativo para el logro de aprendizajes equivalentes por el alumnado, con independencia de su condición social o su lugar de residencia.

25 En la separata de Ecología se sugiere por parte de los estudiantes la "comprensión de las relaciones naturaleza y sociedad, cultura y ambiente, ambiente y desarrollo, política y ambiente" (p.16) y la "reflexión acerca de las problemáticas ecológicas [...] de la provincia de Córdoba, en relación con la calidad de vida del ser humano que la habita. Por ejemplo, la tala indiscriminada de árboles y las inundaciones o las prácticas de monocultivo [...]" (MINISTERIO DE EDUCACIÓN DE LA PROVINCIA DE CÓRDOBA [MEPC]), 2017, p.17).

26 Estos cuestionamientos a la desigualdad social no son propios de nuestra posición didáctica, sino que también forman parte de la agenda de la comunidad científica y organismos de gobierno multilateral (IPBES, 2019). El camino a la sostenibilidad requiere visibilizar, en lo particular, que la alta variación en el nivel de consumo de bienes materiales (alimentos, maderas, etc.), y que el acceso dispar a tales bienes, dado por la inequidad, puede conducir a conflictos sociales (IPBES, 2019).

27 Sistema de producción industrial de alimentos (caso 1), enfermedades que vinculan lo socioambiental, como dengue, chikungunya y zika (caso 2) y pérdida de la biodiversidad en el contexto de degradación ambiental debida a la expansión de la frontera agropecuaria (caso 3).

Enviado el 12/12/2019

Aprobado el 19/09/2020

Contacto:

Universidad Nacional de Córdoba, Facultad de Ciencias Exactas Físicas y Naturales

Departamento de Enseñanza de la Ciencia y la Tecnología

Avenida Dr Vélez Sársfield 299, ciudad de Córdoba

X5000JJC Córdoba, Argentina. 